\title{
Ovarian dermoid eroding into rectum and masquerading as recurrent rectal teratoma
}

This article was published in the following Dove Press journal:

Open Access Surgery

6 March 2010

Number of times this article has been viewed

\section{Somprakas Basu \\ Mohan Kumar \\ Vijay K Shukla}

Department of General Surgery, Institute of Medical Sciences, Banaras Hindu University, Varanasi, India
Correspondence: Somprakas Basu Department of General Surgery, Institute of Medical Sciences, Banaras Hindu University, Varanasi - 221005, India

Tel +9l 5426703383

$\mathrm{Fax}+915422368163$

Email sombasu@hotmail.com

\begin{abstract}
Despite the common incidence of ovarian teratomas, primary rectal teratomas are rare. At times an ovarian teratoma may erode into the rectum and mimic a primary rectal tumor. We report a case of an adolescent girl aged 16 years, who was operated on one and a half years ago for a primary rectal teratoma. Her rectal teratoma reappeared after one year. When an ultrasonographic examination of the abdomen ruled out a secondary pathology and an endoscopic biopsy ruled out malignant conversion, a local recurrence due to incomplete excision was concluded. With the intent to completely excise it from the rectal wall, a laparotomy was carried out which revealed a left ovarian dermoid eroding through the anterior rectal wall. The ovary, along with the dermoid, were excised and the rectal wall defect was primarily closed. Histopathological examination confirmed a benign teratoma of the ovary. This case is presented to highlight the fact that primary rectal dermoids are rare tumors and should be diagnosed with caution. An intensive workup to rule out an ovarian dermoid should always be carried out.
\end{abstract}

Keywords: dermoid cyst, ovary, rectum, teratoma

\section{Introduction}

Benign cystic teratomas of the ovary have been reported in wide age groups ranging from 1 to 91 years. ${ }^{1}$ They are the most commonly neoplasms detected in adolescents and during pregnancy. These are usually asymptomatic until they grow to a large size or produce complications. The rupture of a dermoid cyst into a hollow viscus is common. Though previous reports have documented a fistulous communication with small bowel, colon and bladder, ${ }^{2-4}$ report of erosion of a solid ovarian dermoid into rectum and masquerading as a primary rectal teratoma is not widespread. We present an interesting case of an ovarian dermoid eroding through the rectal wall, which was initially diagnosed as a primary rectal teratoma and was excised transanally but a local recurrence and further workup revealed its origin to be from the left ovary.

\section{Case report}

An adolescent girl of 16 years presented in the Surgical Outpatient department had complaints of recurrent bleeding of the rectum and pain during defecation for the last five months. She had a history of similar episodes of bleeding one and a half years previous for which she was investigated and diagnosed to have a rectal polyp, which was excised transanally and was finally proven to be a benign dermoid cyst arising from the rectum. She denied any history of bleeding disorder, joint pain, irregular bowel habits, and loss of appetite or weight. There was no history of the rectal bleeding coinciding with menstrual bleeding. 
General examination revealed no abnormality barring mild anemia. Abdominal examination did not reveal any lump, hepatosplenomegaly, ascites, guarding or tenderness. Rectal examination revealed a tender swelling in the anterior wall and a rigid sigmoidoscopic examination confirmed a nodular sessile growth of $2 \times 2 \mathrm{~cm}$ from the anterior rectal wall $10 \mathrm{~cm}$ above the anal verge with presence of hair on its surface. A biopsy was taken and was reported as a benign teratoma. An ultrasonographic scan of the abdomen was unremarkable. A computerized tomographic (CT) scan could not be done due to cost. Based on the above, a diagnosis of a recurrent rectal teratoma was made and instead of a repeat transanal excision, an exploratory laparotomy was planned for a curative resection of the intramural component from the rectal wall. On abdominal exploration, the uterus and adnexa were unremarkable barring the left ovary, which was slightly enlarged $(5 \times 4 \mathrm{~cm})$ and was found to be tightly impacted in the rectovaginal pouch. When an attempt was made to dislodge it by blunt and sharp dissection, it was found partially eroding through the anterior rectal wall. The left ovary including its intrarectal extension was excised and the defect in the rectal wall was closed in single layer with interrupted 3-0 polyglactin sutures (Figure 1). The postoperative period was uneventful. Gross examination of the specimen was suggestive of an ovarian teratoma as evidenced by the presence of hair on its surface (Figure 2). The histopathological examination confirmed it as a benign teratoma of the left ovary (Figure 3 ).

\section{Discussion}

Primary rectal teratomas are generally thought to arise from faulty ectodermal cell inclusions during embryogenesis. ${ }^{5}$ These do not usually appear until adulthood. They are more

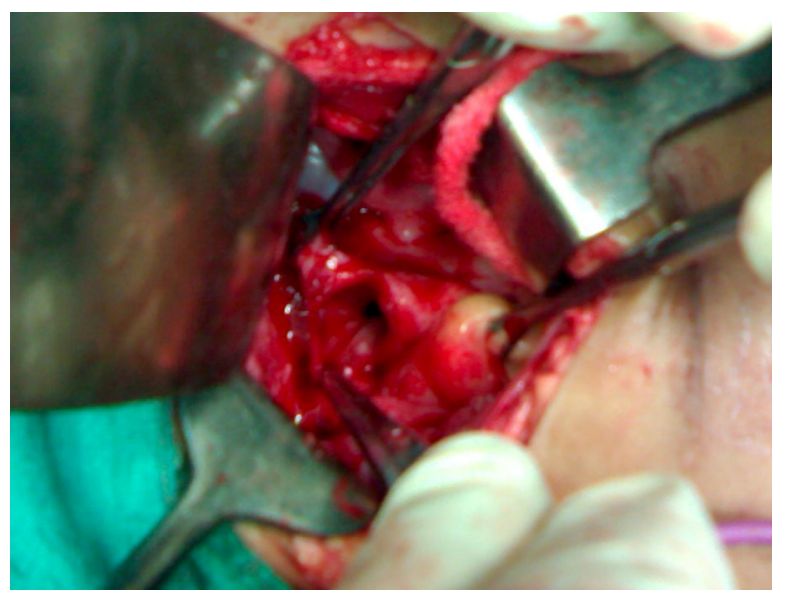

Figure I The defect in anterior rectal wall after excision of the tumor. It was closed primarily in single layer.

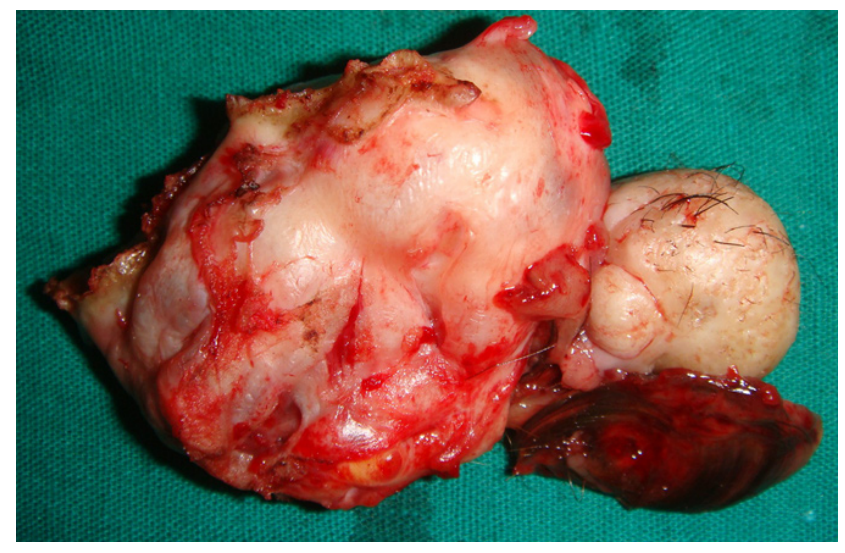

Figure 2 The presence of hair on the intrarectal component of the ovarian tumor: a telltale sign of a dermoid.

commonly seen in females, may be solid or cystic and are diagnosed by the presence of ectoderm-derived components like hair or teeth. Overall, teratomas of the gastrointestinal tract are rare and very few cases of primary rectal teratomas have been reported in the literature. ${ }^{6}$ On the other hand ovarian dermoid is a well-known entity, accounting for 27 to $44 \%$ of all primary ovarian tumors, and for 35 to $58 \%$ of benign ovarian tumors. ${ }^{7}$ Complications of ovarian dermoid include torsion, infection, rupture/perforation and malignant conversion, ${ }^{8}$ of which torsion is the most common complication (16\% cases). ${ }^{9}$ It may rupture intraperitoneally and occasionally into an adjacent viscus. ${ }^{6}$ Rarely these cysts may form fistulous communication with the urinary bladder, small and large bowel. ${ }^{2-4}$ Shiels and colleagues have hypothesized that following a small perforation the close proximity of the cyst to the intestines may cause inflammation and necrosis of

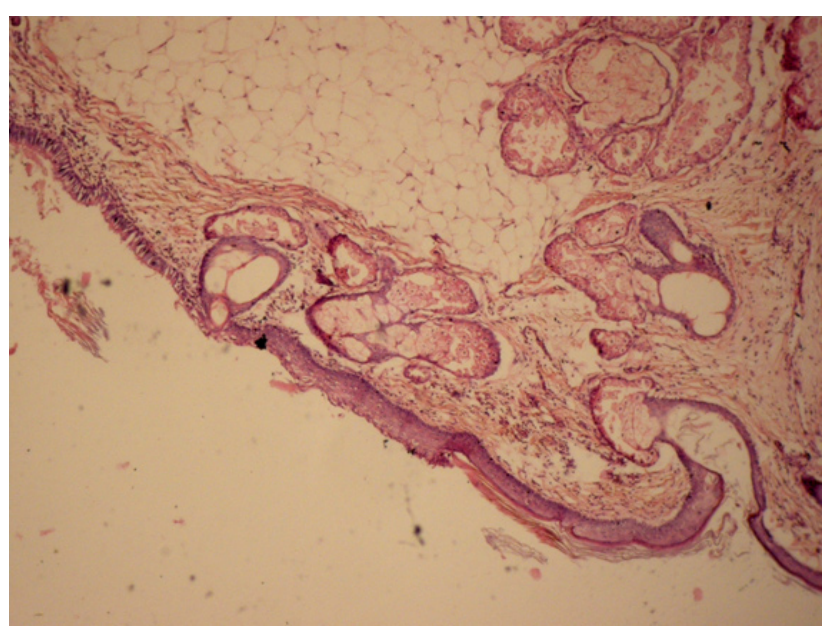

Figure 3 Photomicrograph showing keratinized squamous epithelium with pilosebaceous unit. Presence of respiratory epithelium is also noted in places. Note: Hematoxylin and eosin $\times 50$. 
the bowel wall and finally lead to a fistula formation. ${ }^{10}$ They often themselves present with sudden diarrhea, presence of hairs in stool or recurrent bleeding via rectum. On occasion, ovarian dermoids with malignant transformation have eroded into the intestine. ${ }^{3,9}$

When a teratoma is found in the rectum, it is important to differentiate between a primary rectal teratoma and a teratoma arising primarily from an adjacent organ and eroding into the rectal lumen. According to Fried and Stone ${ }^{11}$ a polypoidal growth or the presence of a well-defined pedicle indicates a primary rectal origin. If there is an intra-abdominal component, a CT scan is diagnostic. But if the ovarian origin evades detection due to small size, the tumor may be mistakenly diagnosed as a primary rectal teratoma. At its initial presentation, in the present case, the polypoidal tumor with a stalk and with a nonmalignant histology probably had prompted a transanal excision, which was an attractive option in view of lesser morbidity. During the second presentation, in the absence of a detectable intra-abdominal component on ultrasonogram, the present case was diagnosed as a local recurrence and the intra-abdominal source was missed. The recurrence was thought to be due to a probable presence of intramural residual tumor tissue in the rectal wall or a probable malignant transformation, which was ruled out in the biopsy. At no time was any suspicion reserved for the ovary based on the fact that an intra-abdominal component was missed on ultrasonogram and a CT scan could not be done. Eventually a laparotomy followed, which as a hind thought was the curative approach.

We present this unusual case to highlight the fact that ovarian teratomas are much more common than primary rectal teratomas. Since penetration of an ovarian tumor into the bowel is known, the lesson learned is that a rectal dermoid should be thoroughly worked up to rule out an ovarian source before calling it primary. Although at times its presentation may be misleading, a strong suspicion towards the ovary as the primary source should be entertained. All such cases should have a CT scan for diagnosis, as an ultrasonogram can miss smaller pathologies. In selected cases diagnostic laparoscopy may help and every effort for a curative resection should be made to prevent morbidity.

\section{Disclosures}

The authors report no conflicts of interest in this work.

\section{References}

1. Pantjola E, Noy MA, Axtmayer RW, et al. Ovarian dermoids and their complications: comprehensive historical review. Obstet Gynecol Surv. 1975;30:1-20.

2. Tabata K, Nagakura K, Hirano I, Baba S. A case of fistula between the urinary bladder and an ovarian dermoid cyst. Hinyokika Kiyo. 2004;50:219-221.

3. Mitui AH, Fujita R, Sugata F, Kienebuchi M, Suzuki K, Sagawa F. A case of ovarian dermoid cyst with malignant transformation perforated into the rectosigmoid colon and small intestine. Endoscopy. 1983;15:331-333.

4. Cebesoy FB, Baskonus I, Mete A, Kutlar I, Aybasti N. Benign ovarian dermoid cyst complicated with rectal fistula formation: an unusual case. Arch Gynecol Obstet. 2009;279:179-181.

5. Takao y, Shimamoto C, Hazama K, et al. Primary rectal teratoma. EUS features and review of the literature. Gastrointest Endosc. 2000;51:353-355.

6. Sakurai Y, Uraguchi T, Imazu H, et al. Submucosal dermoid cyst of the rectum: report of a case. Surg Today. 2000;30:195-198.

7. Scully RE, Young RH, Clement PB. Dermoid cyst (Mature cystic teratoma). In: Scully RE, Young RH, Clement PB editors. Atlas of Tumor Pathology: Tumors of the ovary, maldeveloped gonads, fallopian tube and broad ligament. Washington, DC: Armed Forces Institute of Pathology; 1998:274-284.

8. Okada S, Ohaki Y, Inoue K, Nakajo H, Kawamata H, Kumazaki T. A case of dermoid cyst of the ovary with malignant transformation complicated with small intestinal fistula formation. Radiat Med. 2005;23:443-446.

9. Peterson WF, Prevost EC, Edmunds FT, et al. Benign cystic teratomas of the ovary: a clinicostatistical study of 1007 cases with review of literature. Am J Obstet Gynecol. 1955;70:368-382.

10. Shiels WE, Dueno F, Hernandez E. Ovarian dermoid cyst complicated by an entero-ovarian fistula. Radiology. 1986;160:443-444.

11. Fried H, Stone HB. Four rare rectal tumors. Surg Gynecol Obstet. 1930;50:762-768.
Open Access Surgery

\section{Publish your work in this journal}

Open Access Surgery is an international, peer-reviewed, open access journal that focuses on all aspects of surgical procedures and interventions. Patient care around the peri-operative period and patient outcomes post surgery are key topics. All grades of surgery from minor cosmetic interventions to major surgical procedures are covered. Novel techniques

Submit your manuscript here: http://www.dovepress.com/open-access-surgery-journal

\section{Dovepress}

and the utilization of new instruments and materials, including implants and prostheses that optimize outcomes constitute major areas of interest. The manuscript management system is completely online and includes a very quick and fair peer-review system. Visit http://www.dovepress.com/ testimonials.php to read real quotes from published authors. 